\title{
Mechanical Load in a Circular Rotating Disk With a Shaft for Different Materials Under Steady-State Temperature
}

\author{
Pankaj Thakur ${ }^{1)}$ \\ Satya Bir Singh ${ }^{2)}$ \\ Suresh Kumar'
}

\begin{abstract}
It has been observed that thermal effects increase the value of angular speed required to yield at the internal surface for incompressible/compressible materials. Radial stresses have a maximum value at the internal surface of the rotating disc made of incompressible materials as compared to compressible materials. With the introduction of thermal effects, radial as well as circumferential stresses must be decreased in the absence of mechanical load but when mechanical load is applied, radial as well as circumferential stresses must be increased at the internal surface of a rotating disc with a shaft. A rotating disc is likely to fracture at the bore of the radius.
\end{abstract}

Key words: load, stress, thermal stress, stress analysis, disc, rotating disc, yielding, elasticity and plasticity.

\section{Nomenclature}

$a, b \quad$ - Inner and outer radii of the disc

$\omega \quad$ - Angular velocity of rotation

$u, v, w \quad$ - displacement components

$\rho \quad$ - Density of material

C - Compressibility

$T_{i j}, e_{i j} \quad$ - Stress and Strain rate tensor

$Y \quad-$ Yield stress

$T_{0} \quad$ - Load

E - Young's modulus

$\lambda, \mu \quad$ - Lame's constant

$e_{k k} \quad$ - first strain invariant

$\delta_{i j} \quad-$ Kronecker's delta

$P \quad$ - function of $\beta$

$\beta \quad$ - function of $r$

$k_{1}, k_{2}, K_{1}, K_{2}, d \quad$ - constants

Non dimensional quantities:

$R=r / b ; R_{0}=a / b$ - Radii ratio;

$\sigma_{0}=T_{0} / Y \quad$ - load;

$\Omega^{2}=\rho \omega^{2} b^{2} / Y$ - angular speed;

$\sigma_{r}=T_{r r} / Y$ - Radial stress component;

$\sigma_{\theta}=T_{\theta \theta} / Y$ - Circumferential stress component;

$\Theta_{1}=\alpha E \Theta_{0} / Y$ - Temperature in Kelvin

\section{Introduction}

$\mathrm{R}$ OTATING disks subjected to mechanical and thermal loads have been studied in both linear and nonlinear forms. In the linear analysis, researchers mainly used the infinitesimal elasticity theory [1] for the study of isotropic or anisotropic disks of uniform thickness profiles. In nonlinear cases, scientific literature mainly focused on three aspects, namely nonlinear geometry, material and analysis. Although many earlier studies on rotating disks [2] considered disks with uniform thickness, lately several authors [3-6] considered the nonlinear geometry of rotating disks, emphasizing the importance of variable thickness. Recent studies [7, 8] indicated that stresses in rotating disks (annular or solid) with variable thickness were much lower than those in uniform thickness disks at the same angular velocity. Unlike these studies where disks were subjected to mechanical loads only, many studies can be seen in the literature [9-13] with disks subjected to thermal load only. The accurate determination of stresses in rotating disks is important for an efficient design and material usage in engineering applications such as rotors of rotating machinery, flywheels, shrink fits, turbines, compressors, high speed gear engine and computer disc drives, etc. Pankaj Thakur [14] analyzed stresses in a thin rotating disc with inclusion and edge by using Seth's transition theory. The analysis of thin rotating discs made of isotropic materials has been discussed extensively by Timoshenko and Goodier [15] in the elastic range and by Chakrabarty [16] and Heyman [17] for the plastic range. Güven [18] discussed the problem with rigid inclusion under the assumptions of Tresca's yield condition, its associated flow rule and linear strain hardening. To obtain the stress distribution, Güven matched the plastic stresses at the same radius $r=z$ of the disc. Perfect elasticity and ideal plasticity are two extreme properties of the material and the use of an ad-hoc rule like yield condition amounts to divide the two extreme properties by a sharp line which is not physically possible. When a material passes from one state to another, a qualitatively different state transition takes place.

\footnotetext{
1) Department of Mathematics, IEC University, Baddi, Solan, Himachal Pradesh-174103, INDIA

2) Department of Mathematics, Punjabi University Patiala, Punjab -147002, INDIA

3) Research Scholar, Department of Applied Science, Punjab Technical Univeristy, Punjab, INDIA

Correspondence to: Pankaj Thakur; e-mail: pankay_thakur15@yahoo.com
} 
Since this transition is non-linear in its character and difficult to investigate, researchers have taken certain ad-hoc assumptions like yield condition, incompressibility condition and a certain law which may or may not be valid for the problem. Seth's transition theory [19] does not require these assumptions and thus poses and solves a more general problem from which cases pertaining to the above assumptions can be worked out. This theory utilizes the concept of the generalized strain measure and an asymptotic solution at critical points or turning points of the differential equations defining the deformed field and it has been successfully applied to a large number of problems [6-14]. Seth [20] has defined the generalized principal strain measure as:

$$
\underset{(i=1,2,3)}{e_{i i}=\int_{0}^{A}\left[1-2 e_{i i}^{A}\right]^{\frac{n}{2}-1} d e_{i i}^{A}=\frac{1}{n}\left[1-\left(1-2 e_{i i}^{A}\right)^{\frac{n}{2}}\right]}
$$

where $n$ is the measure and ${ }_{e}^{A}$ is the principal Almansi finite strain components. For $n=-2,-1,0,1,2$ it gives Cauchy, Green Hencky, Swainger and Almansi measures respectively.

The problem of analyzing mechanical load in a circular rotating disc with a shaft in a rotating annular disk mounted on a rigid circular shaft occurs frequently in industrial applications. In this paper, the plastic stresses have been derived by using Seth's transition theory. The results have been discussed numerically and depicted graphically.

\section{Mathematical model}

A thin annular disc of constant density with a central bore of the radius $a$ and the outer radius $b$ is considered. The disc, produced of material of constant density, is mounted on an edge loading. The disc is rotating with the angular speed $\omega$ about the central axis perpendicular to its plane. The disc thickness is assumed to be constant and is taken to be sufficiently small so that the disc is effectively in a state of plane stress, that is, the axial stress $T_{z z}$ is zero. The temperature at the central bore of the disc is $\Theta$.

\section{Boundary conditions:}

The rotating disc considered in the present study is subjected to a temperature gradient field and mechanical load. The inner surface of the disk is assumed to be fixed to a shaft so that isothermal conditions prevail on it. The outer surface of the disk is subjected to mechanical load and maintained at a uniform temperature gradient. Thus, the boundary conditions of the problem are given by:

$$
r=\mathrm{a} u=0 ; r=b, T_{r r}=T_{0}
$$

where $u, T_{r r}$ and $T_{0}$ denote displacement, stress along the radial direction and load applied at the external surface.

\section{Formulation of the Problem}

The displacement components in the cylindrical polar co-ordinate are given by [20]:

$$
u=r(1-\beta), v=0, w=d z
$$

where $\beta$ is the position function, depending on $r=\sqrt{x^{2}+y^{2}}$ only, and $d$ is a constant.
The finite strain components are given by Seth [20] as:

$$
\begin{aligned}
& A_{r r}^{A}=\frac{1}{2}\left[1-\left(r \beta^{\prime}+\beta\right)^{2}\right],{ }^{A} e_{\theta \theta}=\frac{1}{2}\left[1-\beta^{2}\right], \\
& e_{z z}=\frac{1}{2}\left[1-(1-d)^{2}\right],{ }_{A}^{A} e_{r \theta}=e_{\theta z}=e_{z r}=0
\end{aligned},
$$

where $\beta^{\prime}=d \beta / d r$ and the meaning of the superscripts " $A$ " is Almansi.

By substituting eq. (4) in eq. (1), the generalized components of strain become:

$$
\begin{aligned}
& e_{r r}=\frac{1}{n}\left[1-\left(r \beta^{\prime}+\beta\right)^{n}\right], e_{r \theta}=e_{\theta z}=e_{z r}=0 \\
& e_{\theta \theta}=\frac{1}{n}\left[1-\beta^{n}\right], e_{z z}=\frac{1}{n}\left[1-(1-d)^{n}\right]
\end{aligned}
$$

The stress-strain relations for isotropic materials are given by [21]:

$$
T_{t j}=\lambda \delta_{i j} I_{1}+2 \mu e_{i j}-\xi \Theta \delta_{i j},(i, j=1,2,3),
$$

where $T_{i j}$ is the stress components, $\lambda$ and $\mu$ are Lame's constants and $I_{1}=e_{k k}$ is the first strain invariant, $\delta_{i j}$ is the Kronecker's delta and $\xi=\alpha(3 \lambda+2 \mu), \alpha$ being the coefficient of thermal expansion and $\Theta$ is the temperature. Further, $\Theta$ has to satisfy

$$
\nabla^{2} \Theta=0 \Rightarrow \frac{d^{2} \Theta}{d r^{2}}+\frac{1}{r} \frac{d \Theta}{d r} \equiv \frac{1}{r} \frac{d}{d r}\left(r \frac{d \Theta}{d r}\right)=0 \text { or } \frac{d \Theta}{d r}=\frac{k}{r},
$$

which has the solutions:

$$
\Theta=k_{1}\left(\log r+k_{2}\right)
$$

where $k_{1}$ and $k_{2}$ are the constant of integration and can be determined from the boundary condition.

Equations (6) for this problem become:

$$
\begin{aligned}
& T_{r r}=\frac{2 \lambda \mu}{\lambda+2 \mu}\left[e_{r r}+e_{\theta \theta}\right]+2 \mu e_{r r}-\frac{2 \mu \xi \Theta}{(\lambda+2 \mu)}, \\
& T_{\theta \theta}=\frac{2 \lambda \mu}{\lambda+2 \mu}\left[e_{r r}+e_{\theta \theta}\right]+2 e_{\theta \theta}-\frac{2 \mu \xi \Theta}{(\lambda+2 \mu)}, \\
& T_{r \theta}=T_{\theta z}=T_{z r}=T_{z z}=0
\end{aligned}
$$

Substituting eq. (5) in eq. (8), the strain components in terms of stresses are obtained as [25]:

$$
\begin{aligned}
e_{r r}= & \frac{\partial u}{\partial r}-\frac{1}{2}\left(\frac{\partial u}{\partial r}\right)^{2}=\frac{1}{2}\left[1-\left(r \beta^{\prime}+\beta\right)^{2}\right]= \\
& \frac{1}{E}\left[T_{r r}-\left(\frac{1-C}{2-C}\right) T_{\theta \theta}\right]+\Theta \\
e_{\theta \theta}= & \frac{u}{r}-\frac{u^{2}}{2 r^{2}}=\frac{1}{2}\left[1-\beta^{2}\right]=\frac{1}{E}\left[T_{\theta \theta}-\left(\frac{1-C}{2-C}\right) T_{r r}\right] \\
e_{z z}= & \frac{\partial w}{\partial z}-\frac{1}{2}\left(\frac{\partial w}{\partial z}\right)^{2}=\frac{1}{2}\left[1-(1-d)^{2}\right]= \\
= & -\frac{(1-C)}{E(2-C)}\left[T_{r r}-T_{\theta \theta}\right], \\
e_{r \theta}= & e_{\theta z}=e_{z r}=0
\end{aligned}
$$

where $E$ is the Young's modulus and $C$ is the compressibility factor of the material. In term of Lame's 
constant, these are given by

$$
E=\frac{\mu(3 \lambda+2 \mu)}{(\lambda+\mu)}
$$

and

$$
C=\frac{2 \mu}{\lambda+2 \mu}
$$

Substituting equation (5) in equation (8), one gets

$$
\begin{gathered}
T_{r r}=\frac{2 \mu}{n}\left[3-2 C-\beta^{n}\left\{1-C+(2-C)(P+1)^{n}+\frac{n C \xi \Theta}{2 \mu \beta^{n}}\right\}\right], \\
T_{\theta \theta}=\frac{2 \mu}{n}\left[3-2 C-\beta^{n}\left\{2-C+(1-C)(P+1)^{n}+\frac{n C \xi \Theta}{2 \mu \beta^{n}}\right\}\right], \\
T_{r \theta}=T_{\theta z}=T_{z r}=T_{z z}=0,
\end{gathered}
$$

where $C$ is the compressibility factor of the material in term of Lame's constant, given by $C=\frac{2 \mu}{\lambda+2 \mu}$. Equations of equilibrium are all satisfied except

$$
\frac{d}{d r}\left(r T_{r r}\right)-T_{\theta \theta}+\rho \omega^{2} r^{2}=0,
$$

where $\rho$ is the density of the material of the rotating disc.

The temperature satisfies the Laplace equation (7) with the boundary condition $\Theta=\Theta_{0}$ at $r=a, \Theta=0$ at $r=b$, where $\Theta_{0}$ is constant, given by [21] $k_{1}=\frac{\Theta}{\log (a / b)}$ and $k_{2}=-\log b$. Substituting $k_{1}$ and $k_{2}$ from equation (7), one gets

$$
\Theta=\frac{\Theta_{0} \log (r / b)}{\log (a / b)} .
$$

Using equations (10) and (12) in equation (11), one gets a non- linear differential equation in $\beta$ as:

$$
\begin{aligned}
& (2-C) n \beta^{n+1} P(P+1)^{n-1} \frac{d P}{d \beta}= \\
& =\frac{n \rho \omega^{2} r^{2}}{2 \mu}-\frac{n C \xi \bar{\Theta}_{0}}{2 \mu}+ \\
& +\beta^{n}\left[1-(P+1)^{n}-n P\left\{\begin{array}{l}
1-C \\
+(2-C)(P+1)^{n}
\end{array}\right\}\right]
\end{aligned}
$$

Where $\bar{\Theta}_{0}=\frac{\Theta_{0}}{\log (a / b)}$ and $r \beta^{\prime}=\beta P$ ( $P$ is a function of $\beta$ and $\beta$ is a function of $r$ ).

From equation (13), the turning points of $\beta$ are $P=-1$ and $\pm \infty$.

\section{Solution Through the Problem}

For finding the plastic stress, the transition function is taken through the principal stress (see Seth [19, 20], Gupta et al. and Thakur $[22,42]$ ) at the transition point $P \rightarrow \pm \infty$. The transition function $\Upsilon$ is defined as:

$$
\begin{aligned}
& \Upsilon=\left(\frac{n}{2 \mu}\right)\left[T_{\theta \theta}-C \xi \Theta\right]= \\
& =\left[(3-2 C)-\beta^{n}\left\{2-C+(1-C)(P+1)^{n}\right\}-\frac{n C \xi \Theta}{\mu}\right]
\end{aligned}
$$

Taking the logarithmic differentiation of equation (14) with respect to $r$ and using equation (13), one gets

$$
\begin{aligned}
& \frac{d(\log \Upsilon)}{d r}= \\
& -\left[\begin{array}{c}
\beta^{n}\left(\frac{1-C}{2-C}\right)\left[\begin{array}{c}
1-(P+1)^{n}-n(1-C) P \\
\left.+\frac{n \rho \omega^{2} r^{2}}{2 \mu \beta^{n}}+\frac{n \bar{\Theta}_{0}(3-2 C)}{\mu(4-2 C) \beta^{n}}\right]+(2-C) n P \beta^{n}
\end{array}\right] \\
r\left[3-2 C-\beta^{n}\left\{2-C+(1-C)(P+1)^{n}\right\}-\frac{n C \xi \Theta}{\mu}\right]
\end{array}\right]
\end{aligned}
$$

Taking the asymptotic value of equation (15) at $P \rightarrow \pm \infty$ and integrating it, one gets

$$
\Upsilon=K_{1} r^{-1 /(2-C)}
$$

where $K_{1}$ is a constant of integration which can be determined by the boundary condition.

From equation (14) and (16), we have

$$
T_{\theta \theta}=\left(\frac{2 \mu}{n}\right) K_{1} r^{-1 /(2-C)}+\frac{C \Theta_{0} \ln (r / b)}{\ln (a / b)}
$$

Substituting equation (17) in equation (11) and integrating it, one gets

$$
\begin{aligned}
T_{r r} & =\left\{\frac{2 \mu(2-C)}{1-C}\right\} K_{1} r^{-1 /(2-C)}+\frac{C \xi \Theta_{0} \ln (r / b)}{\ln (a / b)} \\
& -\frac{C \xi \Theta_{0}}{\ln (a / b)}-\frac{\rho \omega^{2} r^{2}}{3}+\frac{K_{2}}{r}
\end{aligned}
$$

where $K_{2}$ is a constant of integration, which can be determined by the boundary condition.

Substituting equations (17) and (18) in the second equation of (9), one gets

$$
\beta=\sqrt{1-\frac{2(1-C)}{E(2-C)}\left[\begin{array}{l}
\frac{\rho \omega^{2} r^{2}}{3}-\frac{K_{2}}{r}+\frac{\alpha E \Theta_{0}(2-C)}{\ln (a / b)} \\
{\left[1+\frac{2}{(1-C)} \ln (r / b)\right]}
\end{array}\right]}
$$

Substituting equation (19) in equation (3), one gets

$$
u=r-r \sqrt{1-\frac{2 v}{E}\left[\frac{\rho \omega^{2} r^{2}}{3}-\frac{K_{2}}{r}+\frac{\alpha E \Theta_{0}(2-C)}{\ln (a / b)}\right]}
$$

where $E=\frac{2 \mu(3-2 C)}{(2-C)}$ is the Young's modulus and is $v=\frac{1-C}{2-C}$ passion's ratio in terms of a compressibility factor. Using the boundary condition (3) in equations (18) and (20), one gets 


$$
\begin{aligned}
K_{1} & =\frac{n v}{2 \mu b^{v}}\left[b T_{0}+\frac{\rho \omega^{2}\left(b^{3}-a^{3}\right)}{3}\right]+\frac{\alpha E \Theta_{0}(1-C)(b-a)}{2 \mu \ln (a / b) b^{v}} \\
& -\frac{\alpha E \Theta_{0} n a}{\mu b^{v}}
\end{aligned}
$$

and

$$
K_{2}=\frac{\rho \omega^{2} a^{3}}{3}+\frac{\alpha E \Theta_{0}(2-C)}{\ln (a / b)}\left[1-\frac{2}{(1-C)} \ln \left(\frac{r}{b}\right)\right] .
$$

Substituting the values of the constants $K_{1}$ and $K_{2}$ from equations (17), (18), and (20), respectively, one gets the transitional stresses and displacement as:

$$
T_{\theta \theta}=\left\{\begin{array}{l}
\frac{\rho \omega^{2}\left(b^{3}-a^{3}\right) v}{3 r}\left(\frac{r}{b}\right)^{v}+v T_{0}\left(\frac{r}{b}\right)^{v-1}-2 \alpha E \Theta_{0}\left(\frac{a}{r}\right)\left(\frac{r}{b}\right)^{v} \\
+\alpha E \Theta_{0}(2-C)\left[\frac{(1-C)(b-a)}{r(2-C) \ln (a / b)}\left(\frac{r}{b}\right)^{v}-\frac{\ln (r / b)}{\ln (a / b)}\right]
\end{array}\right\}
$$

$$
T_{r r}=\left\{\begin{array}{l}
\frac{\rho \omega^{2}}{3 r}\left[\left(\frac{r}{b}\right)^{v}\left(b^{3}-a^{3}\right)-r^{3}+a^{3}\right]+\left(\frac{r}{b}\right)^{v-1} T_{0} \\
+\frac{2 \alpha E \Theta_{0}}{v}\left[\frac{a}{r}-\frac{a}{r}\left(\frac{r}{b}\right)^{v}\right] \\
+\frac{\alpha E \Theta_{0}(2-C)}{\ln (a / b)}\left[\ln (r / b)+\frac{(b-a)}{r}\left(\frac{r}{b}\right)^{v}+\frac{a}{r}-1\right]
\end{array}\right\}
$$

$$
u=r-r \sqrt{1-\frac{2 v}{E}\left[\begin{array}{l}
\frac{\rho \omega^{2}\left(r^{3}-a^{3}\right)}{3 r}+\frac{\alpha E \Theta_{0}(2-C)(r-a)}{r \ln (a / b)} \\
+\frac{2(2-C) \alpha E \Theta_{0}}{(1-C)}\left[\frac{\ln (r / b)}{\ln (a / b)}-\frac{a}{r}\right]
\end{array}\right]}
$$

$$
\left|T_{r r}-T_{\theta \theta}=\right| \begin{aligned}
& \frac{\rho \omega^{2}}{3 r}\left[\left(\frac{r}{b}\right)^{v}\left(b^{3}-a^{3}\right)(1-v)-r^{3}+a^{3}\right]+\left(\frac{r}{b}\right)^{v-1}(1-v) T_{0} \\
& +\alpha E \Theta_{0}\left[\begin{array}{l}
2\left(\frac{a}{r}\right) \frac{1}{v(1-C) r}\left(\frac{2 a}{b}\right)^{v} \\
\frac{(b-a)}{r \cdot \ln (a / b)}\left(\frac{r}{b}\right)^{v} \\
+\frac{1}{\log (a / b)(1-v)}\left(\frac{a-r}{r}\right)
\end{array}\right]
\end{aligned} \mid
$$

Initial yielding: It is seen from Fig.2 that $\left|T_{r r}-T_{\theta \theta}\right|$ is maximum at the internal surface (i.e. at $r=a$ ); therefore, yielding will take place at the internal surface of the disc and equation (24) gives:

$$
\begin{aligned}
\left|T_{r r}-T_{\theta \theta}\right|_{r=a} & \left.=\mid \begin{array}{l}
\frac{\rho \omega^{2}\left(b^{3}-a^{3}\right)(1-v)}{3 a}\left(\frac{a}{b}\right)^{v}+\left(\frac{a}{b}\right)^{v-1}(1-v) T_{0} \\
+\alpha E \Theta_{0}\left[\frac{(b-a)}{a \cdot \ln (a / b)}\left(\frac{a}{b}\right)^{v} \frac{2}{(1-C)}\left(\frac{a}{b}\right)^{v}+\frac{2}{v}\right.
\end{array}\right] \\
& =Y(\text { say })
\end{aligned}
$$

where $Y$ is yielding stresses. And the angular speed necessary for the initial yielding is given from equation (25):

$$
\begin{aligned}
& \Omega_{i}^{2}=\frac{\rho \omega_{i}^{2} b^{2}}{Y}=\left|\frac{3 a b^{2}\left[1-\left(\frac{T_{0}}{Y}\right)(1-v)\left(\frac{a}{b}\right)^{v-1}\right]}{\left(\frac{a}{b}\right)^{v}\left(b^{3}-a^{3}\right)(1-v)}\right| \\
& -\left|\begin{array}{l}
\left.\frac{3}{(1-v)\left(1-a^{3} / b^{3}\right)}\right)\left(\frac{\alpha E \Theta_{0}}{Y}\right) \\
{\left[\frac{(1-a / b)}{\ln (a / b)}-\frac{2}{v}(1-v)\left(\frac{a}{b}\right)+\frac{2}{v}\left(\frac{a}{b}\right)^{1-v}\right.}
\end{array}\right|
\end{aligned}
$$

where $1-C=(1-v) / v, \quad \sigma_{0}=T_{0} / Y$ and $\omega_{i}=\frac{\Omega_{i}}{b} \sqrt{Y / \rho}$. We introduce the following non-dimensional components: $R=r / b, \quad R_{0}=a / b, \quad \sigma_{r}=T_{r r} / Y \quad \sigma_{\theta}=T_{\theta \theta} / Y$, $U=u / b, \Theta_{1}=\alpha E \Theta_{0} / Y, \Omega^{2}=\rho_{0} \omega^{2} b^{2} / Y, \quad \sigma_{0}=T_{0} / Y$ and $H=Y / E$. Thermo elastic-plastic transitional stresses, displacement and angular speed from equations (21)-(23) and (26) in a non-dimensional form become:

$$
\begin{aligned}
& \sigma_{\theta}= \frac{\Omega_{i}^{2}}{3 R} v\left(1-R_{0}^{3}\right) R^{v}+v R^{v-1} \sigma_{0} \\
&+\frac{\Theta_{1}}{1-v}\left[\frac{\left(1-R_{0}\right) v}{R \cdot \ln R_{0}} R^{v}+\frac{\ln R}{\ln R_{0}}-2 R_{0}(1-v) R^{v-1}\right] \\
& \sigma_{r}=\left\{\begin{array}{l}
\sigma_{0} R^{v-1}+\frac{\Omega_{i}^{2}}{3 R}\left[R^{v}\left(1-R_{0}^{3}\right)-R^{3}+R_{0}^{3}\right] \\
+\frac{2 \Theta_{1}}{v}\left[\frac{R_{0}}{R}-\frac{R_{0}}{R} R^{v}\right] \\
+\frac{\Theta_{1}}{(1-v) \ln R_{0}}\left[\ln R+\frac{\left(1-R_{0}\right)}{R} R^{v}+\frac{R_{0}}{R}-1\right.
\end{array}\right]
\end{aligned}
$$

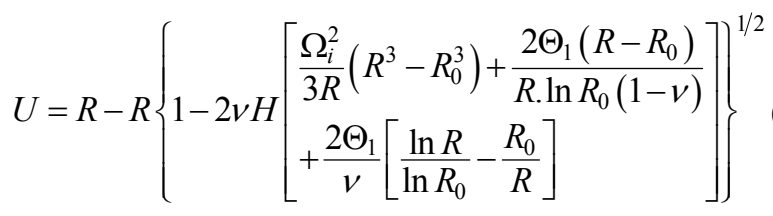

and

$$
\begin{aligned}
\Omega_{i}^{2} & =\left|\frac{3}{\left(1-R_{0}^{3}\right)(1-v)} R_{0}^{v-1}-\frac{3 \sigma_{0}}{\left(1-R_{0}^{3}\right)}\right| \\
& -\left|\left(\frac{3 \Theta_{1}}{(1-v)\left(1-R_{0}^{3}\right)}\right)\left[\frac{\left(1-R_{0}\right)}{\ln R_{0}}-\frac{2}{v} R_{0}^{1-v}+\frac{2(1-v)}{v} R_{0}\right]\right|
\end{aligned}
$$




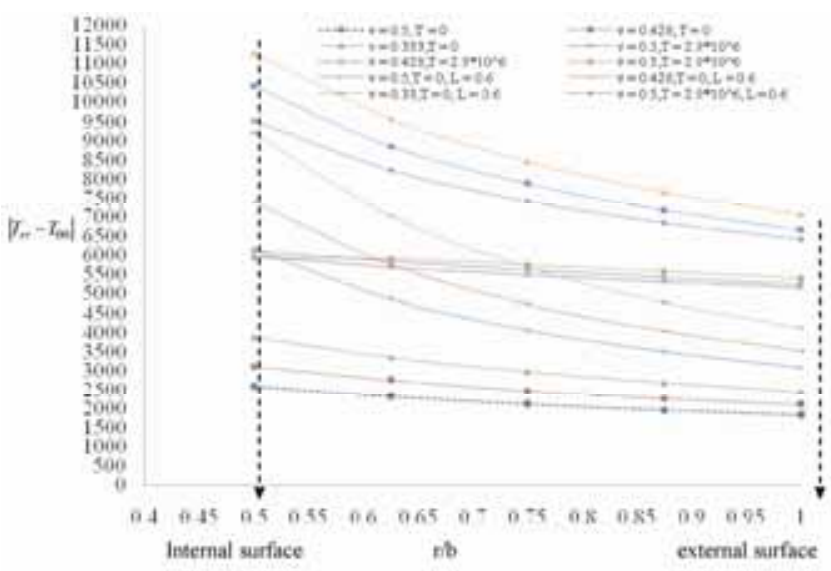

Figure 1. Graph between $\left|T_{r r}-T_{\theta \theta}\right|$ and $r / b$.

Fully plastic state: The angular speed of the rotating disc becomes fully plastic $(v \rightarrow 1 / 2=0.5)$ at the external surface and eq. (24) becomes:

$$
\begin{aligned}
& \left|T_{r r}-T_{\theta \theta}\right|_{r=b} \\
& =\left|\frac{1}{2} T_{0}-\frac{\rho \omega^{2}\left(b^{3}-a^{3}\right)}{6 b}+\alpha E \Theta_{0}\left[\frac{(b-a)}{b \cdot \ln (a / b)}-2\left(\frac{a}{b}\right)\right]\right| \\
& \equiv Y^{*}(\text { say })
\end{aligned}
$$

where $Y^{*}$ is yielding stresses which occur for the fully plastic state. The angular speed required for the disc to become fully plastic is given by equation (31):

$$
\begin{aligned}
\Omega_{f}^{2} & =\frac{\rho \omega_{f}^{2} b^{2}}{Y^{*}}=\left|\frac{6}{1-\left(a^{3} / b^{3}\right)} \cdot\left(\frac{\sigma_{0}}{2}-1\right)\right| \\
& -\left|\frac{6}{1-\left(a^{3} / b^{3}\right)}\left(\frac{\alpha E \Theta}{Y^{*}}\right)\left[\frac{(1-a / b)}{\ln (a / b)}-2\left(\frac{a}{b}\right)\right]\right|
\end{aligned}
$$

where $\sigma_{0}{ }^{*}=T_{0} / Y^{*}$ and $\omega_{f}=\frac{\Omega_{f}}{b} \sqrt{Y^{*} / \rho}$.

Stresses, displacement and the angular speed for the fully plastic state $(v \rightarrow 1 / 2=0.5)$ are obtained from eqs. (27)-(29) and eq. (32) as:

$$
\begin{aligned}
& \sigma_{\theta}=\frac{1}{2 \sqrt{R}}\left[\sigma_{0}+\frac{\Omega_{f}^{2}}{3}\left(1-R_{0}^{3}\right)\right]+ \\
& 2 \Theta_{1}\left[\frac{\left(1-R_{0}\right)}{2 R \cdot \ln R_{0}} R^{1 / 2}+\frac{\ln R}{\ln R_{0}}-\frac{R_{0}}{\sqrt{R}}\right] \\
& \sigma_{r}=\left\{\begin{array}{l}
\frac{\sigma_{0}}{\sqrt{R}}+\frac{\Omega_{f}^{2}}{3 R}\left[\sqrt{R}\left(1-R_{0}^{3}\right)-R^{3}+R_{0}^{3}\right] \\
+4 \Theta_{1}\left[\frac{R_{0}}{R}-\frac{R_{0}}{\sqrt{R}}\right] \\
+\frac{2 \Theta_{1}}{\ln R_{0}}\left[\ln R+\frac{\left(1-R_{0}\right)}{R} R^{1 / 2}+\frac{R}{R_{0}}-1\right]
\end{array}\right\} \\
& U=R-R\left\{1-H\left[\begin{array}{l}
\frac{\Omega_{i}^{2}}{3 R}\left(R^{3}-R_{0}^{3}\right)+\frac{4 \Theta_{1}\left(R-R_{0}\right)}{R \cdot \ln R_{0}} \\
+4 \Theta_{1}\left[\frac{\ln R}{\ln R_{0}}-\frac{R_{0}}{R}\right]
\end{array}\right]\right\}^{1 / 2}
\end{aligned}
$$

$$
\Omega_{f}^{2}=\left|\frac{6}{\left(1-R_{0}^{3}\right)} \cdot\left(\frac{\sigma_{0}}{2}-1\right)\right|-\left|\frac{6 \Theta_{1}}{\left(1-R_{0}^{3}\right)}\left[\frac{\left(1-R_{0}\right)}{\ln R_{0}}-2 R_{0}\right]\right|
$$

\section{Numerical Illustration and Discussion}

Hasan Callioglu et al. [43] analyzed the problems of the stress analysis of functional graded material discs under mechanical and thermal loads. After that, Nitin Chandel et al. [44] investigated the thermo-elastic behavior of a thin circular Functionally Graded Material (FGM) Disk subjected to thermal loads. But in this paper we discuss an isotropic material circular disc subjected to mechanical loads and thermal effects by using Seth's theory.

For calculating the thermal stresses, the angular speed and the displacement based on the above analysis, the following values have been taken numerically: $v=0.5$ (incompressible material e.g. rubber material), 0.42857 (compressible material e.g gold), 0.333 (compressible material e.g. copper or brass material), $E / Y=2$ and $1 / 2$, $\Theta_{0}=0$ and $5811 K, \alpha=255 K$ (for methyl methacrylate) [45], respectively. The curves have been drawn in Fig. 2 between the angular speed $\Omega_{i}^{2}$ required for the initial yielding and various radii ratios $R_{0}=\mathrm{a} / \mathrm{b}$. for $v=0.5$, $0.4285,0.333, L=\sigma_{0}=0,0.3,0.6$ and different values of the temperature $\Theta_{1}=0,2.9 \times 10^{6}$.

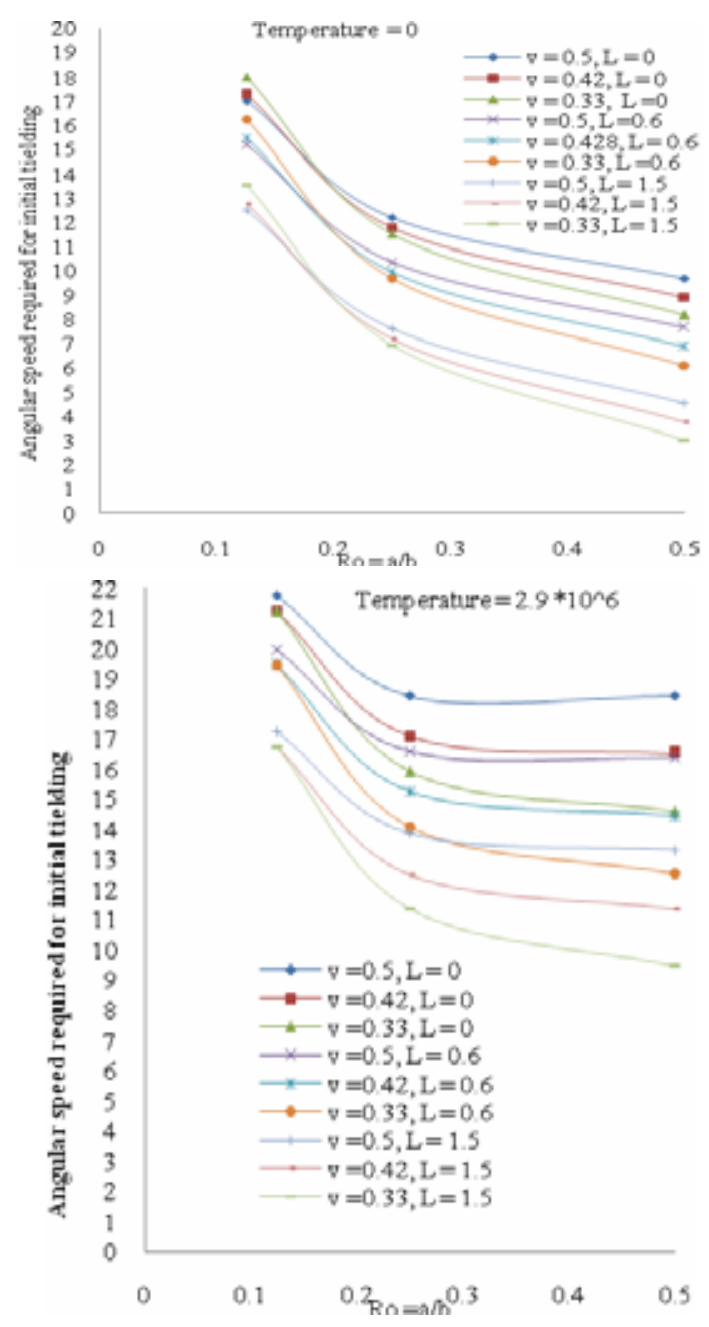

Figure 2. Angular speed required for the initial yielding at the internal surface of the rotating disc with a shaft for $v=0.5,0.428,0.333$ and different values of load $(L)=0,0.3,0.6$ along the radii $R_{0}=a / b$. 
It has been observed that, in the absence of mechanical load, a rotating disc with a shaft required much higher angular speed for incompressible materials (e.g. rubber) as compared to compressible materials (e.g. copper or gold). Mechanical load for rotating discs decreases the angular speed value for incompressible as well as compressible materials.

With the introduction of thermal effect increase, the angular speed value is required to yield at the internal surface for incompressible/compressible materials. In Figures 3 and 4, the curves have been drawn for the thermal stresses distribution and the displacement with respect to the radius $R=r / b$ for the elastic-plastic transitional state and the fully plastic state, respectively. From Figures 3 and 4, it has been seen that the radial stresses have the maximum value at the internal surface of the rotating disc made of incompressible material as compared to that made of compressible material. With the introduction of a thermal effect, radial as well as circumferential stresses must be decreased in the absence of mechanical load but when mechanical load is applied, the applied radial as well as circumferential stresses must be increased at the internal surface of the rotating disc with a shaft. The rotating disc is likely to fracture by cleavage close to the inclusion at the bore.

\section{Conclusion:}

It has been observed that thermal effects increase the value of the angular speed required to yield at the internal surface for incompressible/compressible materials. Radial stresses have the maximum value at the internal surface of rotating discs made of incompressible materials as compared to those made of compressible materials. With the introduction of thermal effects, radial as well as circumferential stresses must be decreased in the absence of mechanical load but when mechanical load is applied, the applied radial as well as circumferential stresses must be increased at the internal surface of the rotating disc with inclusion.

\section{Acknowledgement:}

The authors gratefully acknowledge UGC, New Delhi for providing financial support to carry out this research work under UGC-Major Research Project Scheme (MRPMAJOR-MATH-2013-41603).

\section{References}

[1] TANG,S.: Elastic stresses in rotating anisotropic disks, International Journal of Mechanical Sciences, 1968, 11, pp.509-517.

[2] REDDY,TY, SRINATH,H.: Elastic stresses in a rotating anisotropic annular disk of variable thickness and variable density, International Journal of Mechanical Sciences, 1974, 16(2), pp.85-89.

[3] GUVEN,U.: Elastic-plastic stresses in a rotating annular disk of variable thickness and variable density, International Journal of Mechanical Sciences, 1992, 34(2), pp.133-138.

[4] TUTUNCU,N.: Effect of anisotropy on stresses in rotating discs, International Journal of Mechanical Sciences, 1995, 37(8), pp.873881 .

[5] ERASLAN,AN, ARGESO,H.: Limit angular velocities of variable thickness rotating disks, International Journal of Solids and Structures, 2002, 39, pp.3109-3130.

[6] ERASLAN,AN.: Elastic-plastic deformation of rotating variable thickness annular disks with free, pressurized and radially constrained boundary conditions, International Journal of Mechanical Sciences, 2003, 45, pp.643-667.

[7] ERASLAN,AN, ORCAN,Y.: Elastic-plastic deformation of a rotating disk of exponentially varying thickness, Mechanics of Materials, 2002, Vol.34, No.7, pp.423-432.
[8] ORCAN,Y, ERASLAN,AN.: Elastic-plastic stresses in linearly hardening rotating solid disks of variable thickness, Mechanics Research Communications, 2002, 29(4), pp.269-281.

[9] NODA,N, TSUJI,T.: Steady thermal stresses in a plate of functionally gradient material with temperature-dependent properties, Transactions of the Japan Society of Mechanical Engineers Series A, 1991, 57, pp.625-631.

[10] OBATA,Y, NODA,N, TSUJ,T.: Steady thermal stresses in a functionally gradient material plate, Transactions of the Japan Society of Mechanical Engineers, 1992, 58(A), pp.1689-1695.

[11] TANAKA,K., TANAKA,Y.,WATANABE,H., POTERASU,V.F., SUGANO,Y.: An improved solution to thermo elastic material design in functionally gradient materials: scheme to reduce thermal stresses, Computer Methods in Applied Mechanics and Engineering, 1993, 109, pp. 377-389.

[12] PRAVEEN,G.N., CHIN,C.D., REDDY,J.N.: Thermo elastic analysis of functionally graded ceramic-metal cylinder, ASCE Journal of Engineering Mechanics, 1999, 125, pp.1259-1267.

[13] ZIMMERMAN,R.W., LUTZ,M.P.: Thermal stresses and thermal expansion in a uniformly heated functionally graded cylinder, Journal of Thermal Stresses, 1999, 22, pp. 177-188.

[14] THAKUR,P.: Analysis of Stresses in a Thin Rotating Disc with Inclusion and Edge Loading, Scientific Technical Review, ISSN 1820-0206, 2013, Vol.63, No.3, pp.9-16.

[15] TIMOSHENKO,S.P., GOODIER,J.N.: Theory of Elasticity, 3rd Edition, New York, McGraw-Hill Book Coy., London, 1951.

[16] CHAKRABARTY,J.: Theory of Plasticity, New York: McGraw-Hill Book Coy, 1987.

[17] HEYMAN,J.: Plastic Design of Rotating Discs, Proc. Inst. Mech. Engrs., 1958, 172(1), pp.531-546.

[18] GÜVEN,U.: Elastic - Plastic Rotating Disk with rigid Inclusion, Mech. Struct. \& Mach., 1999, 27, pp.117-128.

[19] SETH,B.R.: Transition theory of Elastic-plastic Deformation, Creep and Relaxation, Nature, 1962, 195:896-897.

[20] SETH,B.R.: Measure Concept in Mechanics, Int. J. Non-linear Mech., 1966, 1(1), pp.35-40.

[21] PARKUS,H., Thermo-Elasticity, Springer-Verlag, Wien, New York, 1976.

[22] GUPTA,S.K., PANKAJ,T.: Thermo elastic - plastic transition in a thin rotating disc with inclusion, Thermal Science, 2007, 11(1):103118.

[23] GUPTA,S.K., PANKAJ,T.: Creep transition in a thin rotating disc with rigid inclusion, Defence Science Journal, 2007, 57(2), pp.185195.

[24] GUPTA,S.K., THAKUR,P.: Creep Transition in an isotropic disc having variable thickness subjected to internal pressure, Proc. Nat. Acad. Sci. India, Sect. A, 2008, 78(I), pp.57-66.

[25] THAKUR,P.: Some Problems in Elastic-plastic and Creep Transition, Ph.D. Thesis, Department of Mathematics, H.P.U. Shimla, India, 2006

[26] THAKUR,P.: Elastic - Plastic Transition in a Thin Rotating Disc having variable density with Inclusion, Structural Integrity and life, Serbia, 2009, Vol.9, No.3, pp.171-179.

[27] THAKUR,P.: Elastic - Plastic Transition Stresses in a transversely isotropic Thick -walled Cylinder subjected to internal Pressure and steady - state Temperature, Thermal Science, 2009, Vol.13, No.4, pp.107-118.

[28] THAKUR,P.: Elastic-plastic transition stresses in a thin rotating disc with rigid inclusion by infinitesimal deformation under steady state Temperature, Thermal Science, 2010, Vol.14, No.1, pp.209219.

[29] THAKUR,P.: Creep Transition Stresses in a thin rotating disc with shaft by finite deformation under steady state temperature, Thermal Science, 2010, Vol.14, No.2, pp.425-436.

[30] THAKUR,P.: Elastic - Plastic Transition Stresses in Rotating Cylinder by Finite Deformation under Steady-State Temperature, Thermal Science, 2011, Vol.15, No.2, pp.537-543.

[31] THAKUR,P.: Effect of transition stresses in a disc having variable thickness and Poisson's ratio subjected to internal pressure, WSEAS TRANSACTIONS on APPLIED and THEORETICAL MECHANICS, 2011, Vol.6, No.4, pp.147-159.

[32] THAKUR,P.: Creep Transition stresses of a Thick isotropic spherical shell by finitesimal deformation under steady state of temperature and internal pressure, Thermal Science, 2011, Vol.15, No.2, pp. S157-S165. 
[33] THAKUR,P.: Stresses in a thin rotating disc of variable thickness with rigid shaft, Journal for Technology of Plasticity, Serbia, 2012, Vol.37, No.1, pp. 1-14.

[34] THAKUR,P.: Deformation in a thin rotating disc having variable thickness and edge load with inclusion at the elastic-plastic transitional stresses, Structural Integrity and life, 2012, Vol.12, No.1, pp.65-70.

[35] THAKUR,P.: Thermo Creep Transition Stresses in a Thick-Walled Cylinder Subjected to Internal Pressure by finitesimal deformation, Structural Integrity and Life, 2012, Vol.12, No.3, pp.165-173.

[36] THAKUR,P.: Creep transition stresses of orthotropic thick-walled cylinder under combined axial load under internal pressure, Facta universitatis - series: Mechanical Engineering, 2013, Vol.11, No.1, pp.13-18.

[37] THAKUR,P.: Effect of stresses in a thin rotating disk with edge load for different materials, Journal for Technology of Plasticity, 2013, Vol.38, No.1, pp. 43-55.

[38] THAKUR,P., SINGH,S.B., KAUR,J.: Elastic-plastic transitional stresses in a thin rotating disc with shaft having variable thickness under steady state temperature, Integritet i vek konstrukcija, 2013, Vol.13, No.2, pp. 109-116,

[39] THAKUR,P.: Finitesimal deformation in a transversely isotropic thin rotating disc with rigid shaft, Journal for Technology of Plasticity, 2013, Vol.38, No.2, pp.143-156.
[40] THAKUR,P., SINGH,S.B., KAUR,J.: Thickness variation parameter in a thin rotating disc by finite deformation, FME Transaction, 2013, Vol.41, No.2, pp. 96-102.

[41] THAKUR,P., SINGH,S.B., KAUR,J.: Elastic-plastic transitional stress in a thin rotating disc with shaft having variable thickness under steady state temperature, Kragujevac Journal of Science, Serbia, 2014, 36, pp. 5-17.

[42] THAKUR,P.: Steady thermal stress and strain rates in a rotating circular cylinder under Steady State Temperature, Thermal Science, Vinča Institute of Nuclear Sciences, Belgrade, Serbia, 2014, Vol.18, No.1, pp. S93-S106.

[43] CALliOGLU,H., SAYER,M., DEMAIR,E.: Stress analysis of functionally graded discs under mechanical and thermal loads, Indian Journal of Engineering \& Material Sciences, 2011,18, pp. 111-118.

[44] CHANDEL,N., MANTHENA,V.R., KUMAR,N.: Thermo-elastic behavior of a Thin Circular Functionally Graded Material (FGM) Disk Subjected to Thermal Loads, Int. J. on Recent and Innovation Trends in Computing and Com., 2015, 3, pp. 72-74.

[45] LEVITSKY,M., SHAFFER,B.W.: Residual Thermal Stresses in a Solid Sphere form a Thermo setting Material, Jr. of Appl. Mech., Trans. of ASME, 1975, Vol.42, No.3, pp. 651-655.

Received: 19.01.2015. Accepted: 27.02.2015.

\title{
Mehaničko opterećenje u kružno obrtnom disku sa osovinom za različite materijale pri stabilnoj temperaturi
}

\begin{abstract}
Uočeno je da uvođenje temičkog efekta povećava zahtevanu vrednost ugaone brzine za tečenje na unutrašnjoj površini za nestišljive/stišljive materijale. Radijalni naponi imaju maksimalnu vrednost na unutrašnjoj površini obrtnog diska izrađenog od nestišljivog materijala u poređenju sa stišljivim materijalom. Radijalni naponi imaju maksimalnu vrednost na unutrašnjoj površini obrtnog diska izrađenog od nestišljivog materijala u poređenju sa stišljivim materijalom. Sa uvođenjem temičkog efekta radijalni isto kao i tangencijalni naponi moraju se smanjiti kada nema mehaničkog opterećenja, ali kada dejstvuje mehaničko opterećenje tada se radijalni kao i tangencijalni naponi moraju povećati na unutrašnjoj površini obrtnog diska s osovinom. Lom obrtnog diska je verovatan u blizini centralnog otvora.
\end{abstract}

Kljućne reči: opterećenje, naponsko stanje, termičko opterećenje, analiza napona, disk, rotacioni disk, tečenje materijala, elastičnoplastičnost.

\section{Механические напряжения в круглых вращающихся дисках с валом для различных материалов при постоянной температуре}

\begin{abstract}
Было отмечено, что введение теплового эффекта увеличивает требуемое значение угловой скорости потока на внутренней поверхности для несжимаемых / сжимаемых материалов. Радиальные усилия имеют максимальное значение на внутренней поверхности вращающегося диска, изготовленного из несжимаемого материала по сравнению с сжимаемым материалом. Со введением теплового эффекта должны быть уменьшены радиальные напряжения, а также и касательные напряжения, если нет механических напряжений, но когда действуют механические нагрузки, то и радиальные и касательные напряжения необходмо увеличить на внутреннюю поверхность вращающегося диска с валом. Лом вращающегося диска, скорее всего и чаще всего происходит рядом с центральным отверстием.
\end{abstract}

\section{Charge mécanique dans le disque rotatif circulaire avec l'axe pour les différents matériaux à température stable}

\begin{abstract}
On a constaté que l'introduction de l'effet thermique augmentait la valeur exigée de la vitesse d'angle pour le cédage sur la surface intérieure chez les matériaux incompressibles / compressibles. Les tensions radiales ont la valeur maximale sur la surface intérieure du disque rotatif qui est produit en matériau incompressible en comparaison avec le matériau compressible. Avec l'introduction de l'effet thermique les tensions radiales ainsi que celles tangentielles doivent décroître quant il n'y a pas de charge mécanique mais quand la charge mécanique est appliquée les tensions radiales et tangentielles doivent augmenter sur la surface intérieure du disque rotatif avec l'axe. La fracture du disque rotatif est probable à proximité de l'ouverture centrale.
\end{abstract}

Mots clés: charge, état de tension, charge thermique, analyse de tension, disque, disque rotatif, cédage du matériau, élasticité plastique. 